\title{
Pre Training Determinants and Training Effectiveness in Public Sector Organizations; In the Case of Dire Dawa Administration, Ethiopia
}

\author{
Amensis Gudeta \\ Department of Public Administration and Development Management, Dire Dawa University, Ethiopia \\ P.O.Box:1362 Dire Dawa University, Dire Dawa, Ethiopia \\ Senaitt Argaw \\ Department of Public Administration and Development Management, Dire Dawa University, Ethiopia \\ P.O.Box:1362 Dire Dawa University, Dire Dawa, Ethiopia
}

\begin{abstract}
This study focused on particular subset of factors determining training effectiveness namely to examine the effect of pre training dynamics trigger effective training, in public sector organizations. A survey questionnaire was used to gather data to answer designed research questions. Survey questionnaires were distributed to 385 sample respondents to collect the primary data selected from six public organizations. The study analyzed collected data using both descriptive and inferential statistics. The findings revealed training need assessment, setting training objective/goal, trainee and trainer selection, employee perception and desire for training positively associated with training effectiveness. Thus, the study urges public organizations to execute training programs through due consideration of pre training determinants impeding training effectiveness.
\end{abstract}

Keywords: training effectiveness, pre training determinants, public sector

DOI: $10.7176 / \mathrm{DCS} / 11-1-01$

Publication date: January $31^{\text {st }} 2021$

\subsection{Introduction}

Public sector capacity emerges from a range of factors which jointly shape civil servants' ability and incentives to perform, and thus the effect of initiatives in any one area depend on what happens with regard to other areas (McCourt, W. \& Eldridge, D., 2003). Effective human resource capital and the quality of employees are considered as crucial precondition and key driver for an organization's development and sustainable success (European Commission, 2009). Nonetheless, individual capacity and learning of how to do things matters; particularly in environments when governments have only recently been reestablished, many new legal provisions and business processes are being introduced in the public administration.

As organizations strive to compete in the global economy, differentiation on the basis of the skills, knowledge, and motivation of their workforce takes an increasing importance. A report by the American Society for Training and Development shows U.S. organizations alone spend more than \$126 billion annually on employee training and development (Paradise, A., 2007). Hence capacity needs to be built is beyond argument. The effectiveness of the civil service is crucial to the development of African economy yet civil services in Africa, with very few exceptions, are not working well. Consequently, to ensure their efficacy training is inevitable. Nonetheless, Omar et al., (2009); Fischer (2011), Driskell, (2011), and Noe and Wilk, (1993) suggest training is affected by financial constraint, failure in strategic planning, high cost, employees' motivation, lack of managerial support, openendedness and employee attitude, modalities of training delivery, content of the training, the ability of the trainee and individual characteristics including motivation, attitudes, behaviors and self-efficacy.

The delivery of efficient and effective training is required to enhance the productivity of employees and improve their performance. Training effectiveness is the relationship between the input variables, output variables and the process or transfer factor. Bimpitsos \& Petridou, (2012) advocate a successful systematic approach is a result of frequent evaluation and previous testing. Furthermore, to improve effectiveness in training programs, organizations should give special attention to employee's participation in designing training methods and modules. Participatory training design motivates the workforce to learn objectively leading to incremental performance development and accelerated professional commitment. However, most of public sector organizations put their employees in to different training because they have a budget allotted following the general assertion training greases efficiency or productivity.

In recent past the need to design, develop, and present effective programs got acute awareness of key stakeholders (including trainees, trainers, senior and line management, and training centers) to increase participation in training activities. Such activities may range from relatively short skills-based workshops to longer-term programs. However, for all the apparent enthusiasm for such programs, there are several determinants that impede organizations participation in training ranging from time pressures and costs to doubts that any tangible 
benefits will result (Mabey, C \& Thomson, A., $2000 \& 2001$ ).

Effective training delivery should be carried out and guided by collaborative training plan and the delivery should be highly participative and practice based. Training should be trainee- centered. Trainees should also encourage participation and sharing views in the training session (Ethiopian Civil Service University, 2009). In Ethiopia in general and Dire Dawa Administration public sector organizations in particular, the need for implementing new reform tools such as Kuizen, BPR and BSC as a strategy to foster good governance is getting extensive attention. The number of employees assigned for training and the frequency of training is also increasing in alarming rate. Therefore, the need for training effectiveness assessment should be precedence while the government is spending public money. Upon this the study planned to answer what are pre training determinants and to what extent each correlates affecting training effectiveness along their implication?

\subsection{Objective of the study}

The study intended to address specific objectives mentioned hereafter,

a. Identifying pre training determinants affecting the effectiveness of training in public sector organizations,

b. Examining the extent of each determinant affects the effectiveness of training in public sector organizations,

\subsection{Training and training effectiveness}

Guest (1997) opined that training and development programs are one of the vital human resource management practices positively affects the quality of the workers knowledge, skills and capability and thus results in higher employee performance on job. Closing the skills gap is now a critical area of human resource development for organizations to continuously penetrate the market which requires the human resource management professionals to start the cultivation of the workforce from the recruitment period. Nevertheless, there is the need for customization of skills and all newly hired employees may not possess the required skill. In responding the skills gap and skills deficiency organizations develop programs that will address the problem (Sims, R. S., 2006). Moreover Meyer and Allen, (1991) suggest to perform well on the job effective training programs are important. Training helps to develop the desired knowledge, skills and abilities of the employees.

According to Chiaburu and Tekleab, (2005) training refers to a planned intervention aimed at enhancing the elements of individual job performance. It is all about improving the skills that seems to be necessary for the achievement of organizational goals. Whereas, Mindtools (2016), defined training effectiveness as it is the degree to which something is successful in producing a desired result or success. Wright and Geroy (2001), suggest employee competencies changes through effective training programs. It not only improves the overall performance of the employees to effectively perform the current job but also enhance the knowledge, skills an attitude of the workers necessary for the future job, thus contributing to superior organizational performance. For this there are tasks that should be done before the actual training program takes place. It is, therefore, imperative that preparation and planning are needed by the organization to make sure that the training program is effective.

However, studies advocate there are pre training factors determine training effectiveness. Individual's motivation and willingness to change; their confidence and tenacity to push beyond their limits, all influence learning. Jenny P., (2010), argues that building competencies must involve enhancing self-awareness and personal mastery, without which any significant change is unlikely. Furthermore, motive (the desire to learn and develop); the means (the mechanisms for learning, for example training) and the opportunities (putting learning into practice) which may be beyond the individual's control also determine the success and failure of training (Kirkpatrick, J. \& Kirkpatrick, W. K.., 2009).

Other studies suggest the proportion of time spent by organizations developing training activities was $10 \%$ on pre-course work, $85 \%$ on the learning event and $5 \%$ on follow-up. However, the percentage contribution to learning effectiveness was $26 \%$ due to pre course work; $24 \%$ due to the learning event; and $50 \%$ due to follow up (Britton, B. (2005). This shows the importance of pre training determinants in crafting training program for its effectiveness. Moreover, Barefoot C., (2015) suggested that involving those who are expected to create or support change in defining what success will look like, will lead to a more realistic training plan. A study conducted by Karthik , R., Karthik, R. (2012) indicated that training objectives tell the trainee that what is expected out of him at the end of the training program. Therefore, training objectives are of great significance from a number of stakeholder perspectives; trainer, trainee, designer, evaluator.

\subsection{Methods and procedures \\ 1.4.1 Study design}

The study used cross-sectional method to explore training in public sector organization deployed as strategy to improve employee's knowledge, skill and attitude and scrutinize effectiveness of the same in light of pre training determinants.

\subsubsection{Source of data and data collection procedure}

Both primary and secondary data were used for this study. Structured questionnaires were designed and used to 
collect qualitative and quantitative primary data on factors affecting training effectiveness associated with pre training determinants. Besides, other data were collected through interviewing key informants as a strategy to triangulate data collected via questionnaire. Pre-testing of the questionnaire were applied using $2 \%$ of the total sample size out of sampled or selected public organizations.

\subsubsection{Sample size determination}

The study determined the sample size using Cochran's (1977) sample size calculation formula. Since there is no pervious study conducted on public sector organizations concerning training effectiveness the study took $50 \%$ of trainings provided were effective while the remaining half wasn't effective, keeping other things remain constant. Accordingly, using 5\% of error margin and 95\% level of confidence, the estimated sample size was calculated as follows:

no $=\frac{\left(\mathrm{Z}_{\bar{\alpha}}\right)^{2}}{\mathrm{~d}^{2}} \mathrm{P}(1-\mathrm{P}) \quad \mathrm{n}_{\mathrm{o}}=\frac{\left(\mathrm{Z}_{0.05 / 2}\right)^{2} *(1-0.5) * 0.5}{0.05^{2}}=\frac{(1.96)^{2}}{(0.05)^{2}} 0.5 * 0.5 \approx 385$

The final sample size calculated using the following formula for proportional allocation of categorical data as the nature of pre training tools and instruments applied by public organization is similar with the corresponding training.

$$
\text { If } \frac{n_{0}}{N}>5 \%, \quad \mathrm{n}=\frac{\text { no }}{1+\frac{\mathrm{no}}{\mathrm{N}}} \quad \text { where } n_{o}=\frac{Z^{2} \alpha / 2 p q}{d^{2}}
$$

Where: $\mathrm{N}$ is the total number of target populations from each sector, that is the sum total of employees and trainers of (xi, xii, xii ...xn) organization, $\mathrm{n}=$ the required total sample size, $\mathrm{n}_{\mathrm{o}}=$ the initial sample size. Therefore, the sample size for each stratum was determined as follows; Land development and management bureau (40), Women, youth and children bureau (31), Construction management (58), Finance and economic development bureau (49), Public service and Human resource development bureau (33) and urban development (54). Eventually random sampling techniques were applied to distribute the survey.

\subsubsection{Method of data analysis}

After collecting all the required data using the aforementioned data gathering instruments the data was edited, coded and inserted for analysis. The study deployed both descriptive and inferential statistics to analyze collected data. Collected data were described using in an attempt to identify specific pre training correlates affecting training effectiveness. In addition the study also used Binary Logistic regressions to determine the significance predictor variable in determining training effectiveness in public sector organizations.

\subsection{Result and discussion \\ 1.5.1 Respondent's demographic characteristics}

Respondents' demographic characteristics show that about (34\%) of female while the remaining (66\%) constitutes male respondents. Regarding age about (65.5\%) of respondent's age range from 25 to 35 years; about (32\%) respondent's age fall between 36-45 whilst the residuals was above of 46 years. The study conducted by Henry and Jennifer Ch. N. et al., (2011) show the age of the respondents dominantly fall between 20 and 40 years old. This implies the need for training is inevitable while organizations continued to recruit young employees. Besides, most of respondent's academic achievement (61\%) were BA/BSc degree; $(35 \%)$ of them have MA/MSc degree and the remaining $(16 \%)$ of respondent acquired diploma. This data also align with the finding of the study done by (Asfaw, A.M., et al., 2015).

Concerning employee's position about $(69 \%)$ of sample respondents held non managerial position though the remaining $(31 \%)$ of them were held positions. With respect to respondent's work experience, majority of them which accounts about (39\%) have 1 to 5 years work experience. About (30\%) of them have more 10 years, while $(20 \%)$ and $(11 \%)$ of them have 6-10 years and less than 1 year work experience. At a time of data collection the distribution of respondents those who attended training were (90\%). However, the frequency respondents assigned for training was unlike. Accordingly, about (41\%) them have trained 1 to 3 times, whereas, the residuals $(26 \%)$ and $(35 \%)$ of them have been trained for 4 to 8 and more than eight times respectively.

\subsubsection{Model Summary binary logistic regression}

Table 1 henceforth shows, roughly $53 \%$ and $76 \%$ of the variability of training effectiveness can be predicted from the linear combination of all variables supposed to be an indicator. The Cox and Snell R-square (53\%) is usually an under estimate whereas, the Nagelkerke R-square is estimated at (76.7\%) indicate that the explanatory variables are valuable in predicting training effectiveness. Thus, those variables having significant association with training effectiveness by using binary logistic regression analysis on the data were appropriate. 
Table: 1- Model Summary binary logistic regression

$\begin{array}{lll}-2 \text { Log likelihood } & \text { Cox \& Snell R Square } & \text { Nagelkerke R Square } \\ 73.479^{\mathrm{a}} & .530 & .767 \\ \text { Chi-square } & \text { Df } & \text { Sig. } \\ 8773 & 8 & .362\end{array}$

The above table also shows fitness of predicted and actual value of training effectiveness up on collected data.

The result manifest goodness-of-fit test which yields $\mathrm{X}^{2}$ value of 8.773 at 8 degree of freedom and it is insignificant at $5 \%$ level of significance. This suggests the model was fit to the data well. This entails the null hypothesis of a goodness model fits to the data was acceptable. In other words the Hosmer - Lemeshow goodness of-fit test statistic is not significant which depict the study does not have an evidence to reject the null hypothesis.

\subsubsection{Logistic Regression Analysis}

Logistic regression was used to analyze the effect of each independent variable on training effectiveness, while controlling the other independent/extraneous variables. The statistical significance of the individual regression coefficients is tested using the Wald chi-square statistic. Consequently, need assessment, setting training objectives, employee's desire for training, employee's perception, trainees and trainer selection techniques and criteria were found to be significant predictors. But early preparation, training programs or schedules and training venue found insignificantly associated with dependent variable as it is stipulated on table below. The interpretation of different estimates corresponding to different variables which found significant is analyzed hereafter accordingly:

Employees from selected public agencies implied that organizations typically government institutions which have had conducted training need assessment prior to training were better off in realizing training effectiveness. As of table 4 depicts, the estimated odds ratio was 56.302 which indicate organizations which conduct training need assessment before training took place were 56.302 times more likely to preserve training effectiveness than other organizations.

Government organizations entitled to deliver public service in a number of specialties/sectors through empowering their employees. In this regard organizations provide training via setting training objective had significant effect in achieving effective training. The estimated odds ratio $(\mathrm{OR}=169.941,95 \% \mathrm{CI}=10.032,2878)$ indicates that organization which set training objective were 169.941(169.9\%) times more likely to accomplish training effectiveness. From this one can deduce that public sector organizations failed to set training objective ahead of assigning their employees for training usually fall short to attain effective training designed to capacitate employees.

The other variable the study envisaged was perception about training. Employee perception about training and their desire to attain training have positive association with training effectiveness. In other words training effectiveness provided by public institutions was affected by employee's perception and their desire. The coefficient for employee's perception and their desire about training was estimated at 2.730 and 3.339 respectively and which was found statistically significant $(\mathrm{P}=0.000$ and $0.000<0.05)$ on training effectiveness. The chance of training achieving its intended goal (i.e. effective training) through working on employee's perception and desire was crucial as compared with the reference category. The estimated odds ration of employee's perception and desire were $(\mathrm{OR}=15.331,95 \% \mathrm{CI}=3.489,67.413$ and $\mathrm{OR}=28.200,95 \% \mathrm{CI}=5.156,67.413)$ respectively. This shows public organizations had achieved 15.331 and 28.2 times higher result of effective training with better employee perception and desire for the training.

Further, public sector organizations which carefully scrutinize while selecting trainers through considering trainers' skill, preparedness, experience, compatibility with training subject and other pre conditions yield effective training. This shows the probability of achieving training effectiveness also depends on careful selection of trainer as compared with the reference category. Public organizations follow cautious trainer selection procedures were 21.237 times more likely to attain training effectiveness than those organizations failed to do so. The coefficient for trainee selection was estimated at 2.646 was found statistically significant $(\mathrm{P}=0.002<0.05)$ with dependent variable (training effectiveness). Setting Clear criteria for trainee selection and acting accordingly enables the organization to have effective training as compared with the reference category. The estimated odds ratio of trainee selection were $(\mathrm{OR}=14.098,95 \% \mathrm{CI}=2.546,78.081)$. This depicts organization which has had relevant trainee selection techniques and select trainees accordingly had 14.098 times higher result of attaining effective training. Apart from this the study find out early training preparation, training program/schedule and training venue planned to carry out training association with training effectiveness was insignificant statistically. In other words, the study suggests public organization either plans early or not, schedule of the same and venue doesn't affect training effectiveness keeping other variables constant. Hence, the found statistically insignificant at $\mathrm{P}<0.05$ which was 0.012 for planning training early, 0.043 for training schedule and 0.104 for training venue. 
Table: 2- Binary logistic analysis result

\begin{tabular}{|l|l|l|l|l|l|l|l|l|}
\hline Variables & B & S.E. & Wald & df & Sig. & Exp(B) & \multicolumn{2}{|l|}{ 95\% C.I. for EXP(B) } \\
\cline { 6 - 10 } & & & & & & & Lower & Upper \\
\hline Nessasse(Yes) & 4.031 & 1.045 & 14.883 & 1 & .000 & 56.304 & 7.264 & 436.395 \\
\hline Setobjective(Yes) & 5.135 & 1.444 & 12.653 & 1 & .000 & 169.941 & 10.032 & 2878.696 \\
\hline Earlypre(Yes) & 3.209 & 1.274 & 6.342 & 1 & .012 & 24.759 & 2.037 & 300.911 \\
\hline Trainpro(Yes) & 2.015 & .997 & 4.088 & 1 & .043 & 7.502 & 1.064 & 52.911 \\
\hline Emydesire(Yes) & 2.730 & .756 & 13.053 & 1 & .000 & 15.331 & 3.487 & 67.413 \\
\hline Emyperception(Yes) & 3.339 & .867 & 14.835 & 1 & .000 & 28.200 & 5.156 & 154.251 \\
\hline Trainerselect(Yes) & 3.056 & .963 & 10.063 & 1 & .002 & 21.237 & 3.215 & 140.299 \\
\hline Traineeselect(Yes) & 2.646 & .873 & 9.180 & 1 & .002 & 14.098 & 2.546 & 78.081 \\
\hline Trainingven(Yes) & 1.696 & 1.044 & 2.638 & 1 & .104 & 5.451 & .704 & 42.181 \\
\hline Constant & -11.508 & 2.448 & 22.091 & 1 & .000 & .000 & & \\
\hline
\end{tabular}

Source: Own computation, 2019

Where, $\mathrm{n}=385, \mathrm{p}<0.05,95 \% \mathrm{CI}$

\subsection{Discussion}

Other studies also identified as need assessment affects training effectiveness. Folkes, (2008) suggest effective training programs encourage employees to be equipped with the desired skills and competencies to match new technological advancement. For this as Boardman and Sundquist, (2012) delineated that effectively identify training needs provide specification of the main duties and skill level required. Tai, (2010) also concluded that for effective training to take place a comprehensive needs analysis has to be conducted. It does not help the organization in any way to train individuals who do not require skills upgrading. Further, Rama \& Vaishnavi, (2012) also identified that to maximize the effectiveness of training program an organization needs to use ongoing assessments.

Donaldson, (2010) points out that, to increase the value and return of training, managers ought to have aligned it with the organization's strategy. Which suggest the need for setting training objective which aligns with organizational strategy for training effectiveness is important. Furthermore, alignment between organizational strategy and effectiveness of training is necessary to ensure organizational success (Boardman, C., \& Sundquist, E., 2012). They argue that for training to complement organization's strategy there is need to examine the extent to which training and human resource development are interrelated with the organization's strategy. Our study also found that training conducted through setting training objective in an attempt to be dictated by organizational goal determines training effectiveness.

Training design should be made according to the needs of the employee; those organizations which develop a good training design according to the need of the employees and the organization always get good results (Partlow, D., et al., (1996); Tihanyi, A., et al., (2000); Flynn, T., et al., (2001)). Besides, Tai, (2010) found out that effectiveness of the training can be influence by employee's attitudes to a large extent. Employees with positive attitudes towards effectiveness of training are likely to appreciate training. Moreover, Noe and Wilk, (1993) suggested that attitudes and motivation to learn play a crucial role in achieving training success. Therefore, this study also found that training effectiveness is the outcome of a number of intertwined factors including employees desire to learn.

The finding stipulated in this study also dictum that trainers selection affect realization of training effectiveness which further supported by other scientific enquiry. As Kirkpatrick, (2006) suggest the selection of instructors is critical to the success of a program. Their qualifications should include knowledge of the subject being taught, a desire to teach, the ability to communicate, and skill at getting people to participate. They should also be learner oriented and have a strong desire to meet learner needs. Robotham D., (1995) also suggested that trainers must have awareness and understanding of individual's style to achieve desired outcomes of training. While the study conducted by Driskell, (2011) view the trainer is not a good communicator may bring about ineffective communication and hence failure to achieve the desired results (effectiveness of training).

Another important contextual factor that may influence training effectiveness is whether trainees can choose which training they attend. Studies indicate voluntary participation has been shown to be related to higher motivation to learn, greater learning, increased self-efficacy, and more positive trainee reactions than mandatory attendance (Cohen, D.J. (1990); Hicks, W.D., et al., (1987)). Accordingly, training program should have a definitive statement about the target participants. More so, there is the tendency to deviate from the ideal by feeding participant that is not truly fitted into the training program (Mat N. B., et al., 2008). There is some evidence that the messages trainees receive can influence training effectiveness. According to Martocchio, (1992) manipulated trainee perceptions about the usefulness of training in their organization by providing different instructions at the beginning of training. All trainees received identical training but the group that was lead to believe that the training was valuable demonstrated greater post-training knowledge and efficacy than the group that received a neutral message. Accordingly, our study also found to realize effective training programs it is better to consider and re 
evaluate trainee's selection and perception about training.

\subsection{Conclusion and Recommendation}

The changing nature of work in today's global economy makes knowledge management one of the most salient issues facing human resource development researchers and practitioners. For this a wealth of empirical researches recommends training. Yet, training is not a panacea which will curb all organizational impediments especially public organization setup to deliver complex and diversified services. Building employee's capability through effective training and development programs is inevitable which scholars and practitioners prescribe. However, training is not a simple task that organizations arbitrarily perform. Therefore, this study suggest public organizations to deem pre training determinants such as training need, training goal setting, trainee's desire and perception, trainer selection and so forth which affect training effectiveness.

\section{Reference}

McCourt, W. \& Eldridge, D. (2003).Global human resource management: Managing people in developing and transitional countries, UK: Edward Elgar.

European Commission (2009). Industrial Relations in Europe in 2008. DG Employment and Social Affairs, Brussels.

Paradise, A. (2007). State of the Industry: ASTD's Annual Review of Trends in Workplace Learning and Performance (Alexandria, VA: ASTD).

Omar, M.Z., Kofli, N.T., Mat, K., Darus, Z.M., Osman, S.A. \& Rahman, M.N.A. (2009). Measuring the Outcomes from Industrial Training Program. European Journal of Social Sciences. 8(4), 581-588.

Fischer, R. (2011). "Cross-Cultural Training Effects on Cultural Essentialism Beliefs and Cultural Intelligence", International Journal of Intercultural Relations, 35(6), pp. 767-775.

Driskell, James E. (2011). "Effectiveness of Deception Detection Training: A MetaAnalysis", Psychology, Crime \& Law, 10 (2011) pp. 1-19.

Noe, R.A. and Wilk, S.L. (1993) Investigation of the Factors That Influence Employee's Participation in Development Activities. Journal of Applied Psychology, 78, 291-302.

Bimpitsos, C. and Petridou, E. (2012). A Transdisciplinary Approach to Training: Preliminary Research Findings Based on a Case Analysis. European Journal of Training and Development, 36, 911-929.

Mabey, C \& Thomson, A., (2000). “Achieving Management Excellence.” The Institute of Management (2000) ISBN 10: 0859463141 ISBN 13: 9780859463140.

Mabey C, Thomson A., (2001). The Learning Manager: A Survey of Management Attitudes to Training and Development, Institute of Management.

Ethiopian Civil Service University (2009). Training policy and guideline. Addis Abeba, Ethiopia. (Unpublished)

Guest, D. (1997). Human resource management and performance: A review and research agenda. International Journal of Human Resource Management, 8 (3), 263-276.

Sims, R. S. (2006). Human Resource Development: Today and Tomorrow. IAP.

Meyer, J. P., \& Allen, N. J. (1991). A three-component conceptualization of organizational commitment. Human Resource Management Review, 1(1), 61-89.

Chiaburu, D.S., and Tekleab, A.G. (2005). Individual and contextual influences on multiple dimensions of training effectiveness. Journal of European Industrial Training, Vol. 29 No. 8, pp. 604-26.

Mindtools. (2016). Kirkpatrick's four-level training evaluation model.

Wright, P. \& Geroy, D. G. (2001). Changing the mindset: the training myth and the need for word-class performance. International Journal of Human Resource Management 12, 4, 586-600.

Pearson, J. (2010). 'A Learning Package for Capacity Development: Learning to Change Capacity Development Practice'.

Kirkpatrick, J. \& Kirkpatrick, W.K. (2009). The Kirkpatrick four levels: A fresh look after 50 years, 1959-2009. Retrieved December 27, 2018

Britton, B. (2005). 'Organisational Learning in NGOs: Creating the Motive, Means and Opportunity' (Praxis Paper 3), INTRAC, UK.

Barefoot Collective (2015). 'The Barefoot Guide 4: Exploring the Real Work of Social Change'.

Karthik, R. (2012), “Training and Development in ITI Limited - Bangalore”, Advances In Management, Vol. 5 (2), pp. 54-60.

Henry Ongori, Jennifer Chishamiso Nzonzo (2011). Training and Development Practices in an Organization: An Intervention to Enhance Organizational Effectiveness, vol. 2(4).

Asfaw, A.M., Argaw, M.D. and Bayissa, L. (2015). The Impact of Training and Development on Employee Performance and Effectiveness. Journal of Human Resource and Sustainability Studies, 3, 188-202.

Folkes G. T. (2008). Consumer information processing: Attributing effects to causes. Paper presented at the Second Annual Conference of the Association for Consumer Research, College Park, Maryland, and 
September 2008 .

Boardman, C., \& Sundquist, E. (2012). Toward Understanding Work Motivation Worker Attitudes and the Perception of Effective Public Service, The American Review of Public Administration, 39(5), 519-535

Tai, W. T., (2010). Effects of training framing, general self-efficacy and training motivation on trainee's training effectiveness, Personal Review, 35(1), pp.51-65

Rama, M. \& Vaishnavi. R. (2012). "Measuring Training Effectiveness: A Study in a Leading Retailing Industry in A Metropolitan City", International Journal of Multidisciplinary Management Studies, 2(4), pp. 16-25

Donaldson, L. (2010). A rational basis for criticism of organizational economics: a reply to Barney. Academy of Management Review, Vol. 15, pp. 394-401., ISSN: 0363- 7425

Partlow, D., Chibum, K. \& Tekleab, A., (1996). Individual and contextual influences on multiple dimensions of training effectiveness. Journal of European Industrial Training. 29(8) 604-26.

Tihanyi, A., Lord, M. \& Scott, J. (2000). Acquiring new knowledge the role of retaining human capital in acquisitions of high-tech firms. The Journal of High Technology Management Research, pp. 11, 2, 295 - 319.

Flynn, T., Waite, K. \& White, P. (2001). Analysis by paralysis: the pension purchase decision process. International Journal of Bank Marketing, pp. 24. (1) 5-23.

Noe, R.A. and Wilk, S.L. (1993). Investigation of the factors that influence employees participation in development activities", Journal of Applied Psychology, Vol. 78, pp. 291-302

Donald L. Kirkpatrick and James D. Kirkpatrick, (2006). Evaluating Training Programs: The Four levels. Third edition. Barrett-Koehler Publishers.

Robotham, D. (1995). "Self-Directed Learning: The Ultimate Learning Style?” Journal of European Industrial Training, 19(7), pp. 3-7.

Driskell, James E. (2011). "Effectiveness of Deception Detection Training: A Meta Analysis", Psychology, Crime \& Law, 10 pp. 1-19.

Cohen, D.J. (1990). What motivates trainees? Training and Development Journal, 91-93.

Hicks, W.D. \& Klimoski, R.J. (1987). Entry into training programs and its effects on training outcomes: A field experiment. Academy of Management Journal, 30, 542-552.

Mat N. B. and Saad A. M., (2008). Evaluation of Effectiveness of Training and Development: The Kirkpatrick Model. Asian Journal of Business and Management Sciences Vol. 2 No. 11, 14-24.

Martocchio, Joseph J. 1992. Microcomputer Usage as an Opportunity: The Influence of Context in Employee Training. Personnel Psychology 45:529-552. 